\title{
Política social, desarrollo territorial o trampa de pobreza: Caso Mártir de Cuilapan, Guerrero
}

\author{
Social Policy, Territorial Development or Poverty Trap: Case of Mártir de \\ Cuilapan, Guerrero
}

Política social, desenvolvimento territorial ou armadilha da pobreza: Caso Mártir de Cuilapan, Guerrero

Iván Sánchez Ignacio Universidad Autónoma de Guerrero, Centro de Investigación y Posgrado en Estudios Socioterritoriales, Guerrero, México ivansanz_i@hotmail.com https://orcid.org/0000-0002-1354-7115

Pedro Vidal Tello Almaguer Universidad Autónoma de Guerrero, Centro de Investigación y Posgrado en Estudios Socioterritoriales, Guerrero, México pvidalt@hotmail.com https://orcid.org/0000-0003-0473-3562 


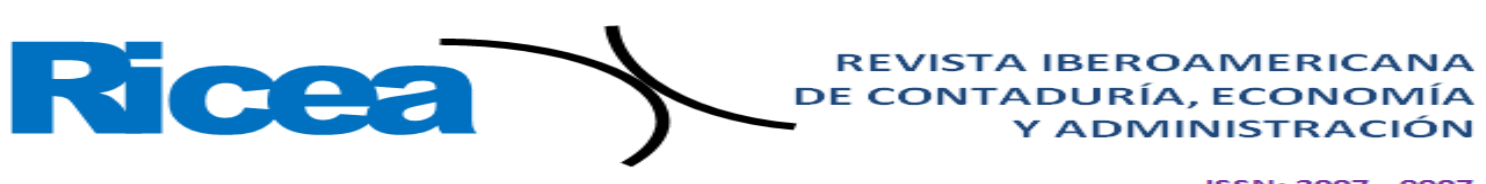

\section{Pobreza y sustentabilidad social}

El análisis sobre la pobreza tiene una amplia historia en los ámbitos de la reflexión económica, sociológica y filosófica. En Europa, comienza con el economista Adam Smith (1958), quien esbozó el fenómeno de la siguiente manera: "Los pobres son quienes solamente pueden sostenerse por su trabajo asalariado, pero un trabajador 'es rico o pobre, está bien o mal, en proporción al precio real de su labor' y este precio está relacionado con las cantidades de bienes que él pueda adquirir" (p. 31). Lo cual es base fundamental de su teoría económica al plantear que el máximo nivel de bienestar social se genera por medio del mercado.

Para Marx (2014), la naciente clase capitalista inglesa cambió el sistema de explotación feudal por el de explotación capitalista, donde una masa de hombres es despojada repentina y violentamente de sus medios de subsistencia (tierras y medios de producción) y son lanzados al mercado de trabajo como hombres libres y desheredados, lo que convierte a hombres y mujeres en pobres que no tiene nada que vender más que su fuerza de trabajo.

El filósofo estadounidense John Rawls (2006) considera que los menos aventajados son quienes enfrentan escasez de bienes sociales primarios y como ciudadanos no pueden desarrollarse adecuadamente para ejercer plenamente sus facultades morales al no contar con derechos, libertades, oportunidades, poderes, ingresos y riqueza. La determinación de los bienes primarios depende de las necesidades y habilidades humanas, de sus fases y requisitos normales de nutrición y de las relaciones de interdependencia social, entre otras cosas (Rawls, 2006).

En tanto que para Amartya Sen (2000) una propuesta igualitaria aceptable no debería concentrarse solo en el acceso a los bienes sociales primarios, sino también, sugiere este economista indio, concentrar la atención en las capacidades básicas de las personas. De acuerdo con su enfoque, la pobreza se concibe como la privación de capacidades básicas, lo cual tiene diversas manifestaciones: mortalidad prematura, un grado significativo de desnutrición, alta morbilidad, elevado nivel de analfabetismo, baja esperanza de vida, el sexo y los roles sociales, entre otros aspectos; que no se deben exclusivamente a la carencia de ingresos, pero que forman parte del criterio habitual con el que se identifica la pobreza.

Galo y Zeira (citados en Mayer-Foulkes, 2007) sugieren que la trampa de pobreza es la restricción crediticia que no permite a la población acceder a la alimentación, educación y salud, y los sitúa en el círculo vicioso causante de la pobreza transgeneracional. Y volviendo a Sen (2000), la trampa de pobreza se determina por la privación de las capacidades básicas de los individuos, que se refleja en la deficiencia del desarrollo de capital humano e impacta en las capacidades 


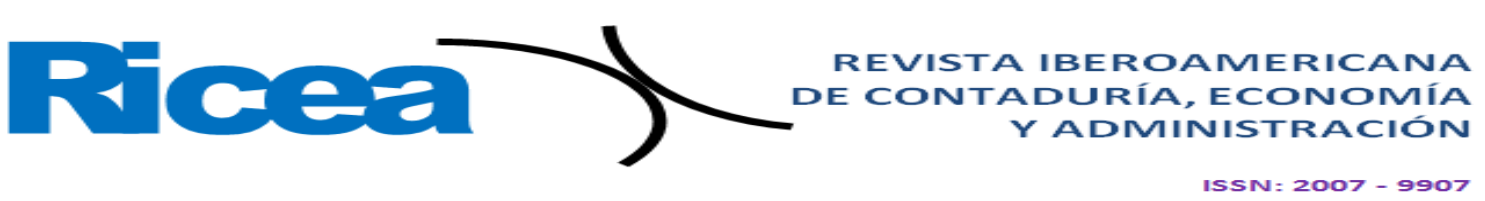

construcción de una nueva lógica de participación social para el desarrollo del buen vivir, comprometida con la preservación del medio ambiente, los saberes locales, el logro de la justicia y la equidad.

El principal objetivo de las instituciones es el de ser el hilo conductor de la coordinación y colaboración entre distintos órdenes gubernamentales, actores sociales y ciudadanos que participen en la elaboración del diagnóstico de los problemas sociales del territorio, para fortalecer y diseñar los programas para el desarrollo local sustentable. Estas políticas sociales ejercen una influencia importante para la territorialización, entendida como el establecimiento y respeto de las formas representativas de relaciones sociales establecidas de manera colectiva o individual con las instituciones principales, y a su vez reconfiguran el territorio con base en tres elementos principales: reconstrucción del tejido social, potencialización de las ramas económicas en los espacios productivo y la naturaleza.

Sin embargo, el concepto de política social no toma en cuenta las categorías de espacio, territorio y territorialización, que contribuyen a la comprensión del comportamiento de la sociedad en la identificación de sus problemas y necesidades sociales, así como en el diseño de sus principales acciones para la integración y organización solidaria de la sociedad, con el objetivo de procurar el bienestar social.

Espacio, territorio y territorialización son categorías básicas que se deben tener en cuenta para analizar la implementación de una política social, con el fin de entender los procesos que constituyen la esencia de la espacialidad de la vida social y los aspectos que le afectan. Se debe tomar en cuenta, asimismo, que las inversiones deben establecer donde se garanticen beneficios y sean rentables, y siempre que se reúnan las condiciones de infraestructura básica, estabilidad social, vías de comunicación y un mercado local dinámico, aspectos que se consideran necesarios también para implementar políticas sociales.

El enfoque de espacio ha venido cobrando importancia desde las distintas perspectivas de análisis. Este permite observar el carácter integrador del conocimiento de la naturaleza y la sociedad en la investigación territorial. Daniel Hiernaux (1993) define el espacio "como un conjunto de formas representativas de relaciones sociales del pasado y del presente y por una estructura que pueda expresar en las relaciones sociales, a su vez indicativas de procesos" (p. 103). Desde la geografía crítica latinoamericana, los aportes de Santos (2000) esbozan una definición de espacio como un conjunto indisoluble de sistemas de objetos y sistemas de acciones; sus categorías analíticas internas son: el paisaje, la configuración territorial, la división territorial del trabajo, el espacio producido o productivo, las rugosidades y las formas-contenido. En suma, se entiende al 


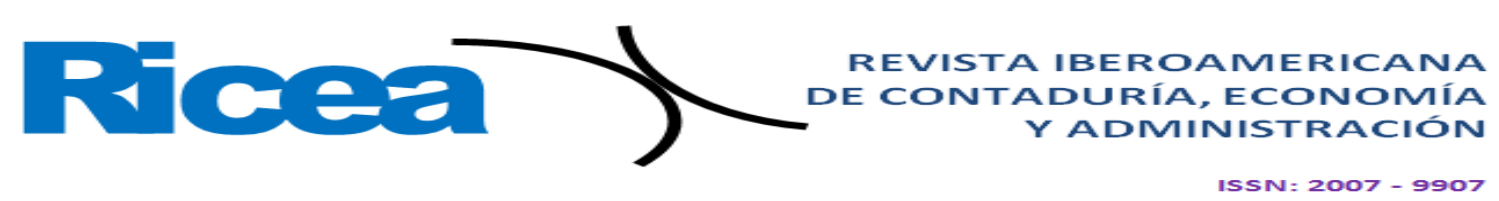

pequeños contribuyen a que los productores locales no estén estimulados a dedicarse a actividades productivas que les permitan intercambiar el excedente del producto de su trabajo, por lo tanto, no hay ocupación y producción constante y se recurre al autoconsumo.

Ahora bien, en términos generales, las políticas sociales se han construido con un enfoque homogéneo para enfrentar los fenómenos sociales (pobreza, desigualdad y discriminación social), sin considerar las diferencias económicas, sociales y territoriales que se tienen en el país, entidades federativas y municipios.

En este sentido, la centralización en el diseño y ejecución de las políticas sociales se refleja en una desvinculación con el territorio. Por lo tanto, no se puede pensar en impulsar políticas sociales sin la participación de los actores sociales en las diferentes etapas: diseño, operación, gestión, evaluación y monitoreo. Además, se deben de fomentar acuerdos locales de desarrollo más simétricos que reflejen los intereses de la comunidad, como mecanismo que permita revertir la distancia entre los ciudadanos y el Gobierno, considerando las particularidades de su territorio.

\section{Metodología}

Para el cumplimiento del objetivo general de la presente investigación, se aplicó el enfoque mixto. De acuerdo con Hernández, Fernández y Baptista (2010) es “un conjunto de procesos sistemáticos, empíricos y críticos de investigación e implican recolección y análisis de datos cuantitativos y cualitativos, así como su integración y discusión conjunta” (p. 546). Dicho conjunto permite identificar y valorar los aspectos de carácter socioeconómico y territorial.

La recopilación de información de campo se realizó a través de la técnica de entrevista, la cual, en términos de Guber (2001), es lo siguiente:

Una situación cara-a-cara donde se encuentran distintas reflexividades, pero, también, donde se produce una nueva reflexividad. Entonces la entrevista es una relación social a través de la cual se obtiene enunciado y verbalización en una instancia de observación directa y de participación (p. 76).

La clasifica, además, en entrevista semiestructurada informal o no directiva, estructurada y cuestionario preestablecido, grupos focalizados en una temática, y clínicas.

En la investigación se utilizaron las técnicas de entrevista estructurada y semiestructurada. En la primera, el investigador formula las preguntas y el entrevistado se subordina a la concepción del contexto, dinámica y categorías determinadas por él; y en la segunda, el investigador desarrolla 


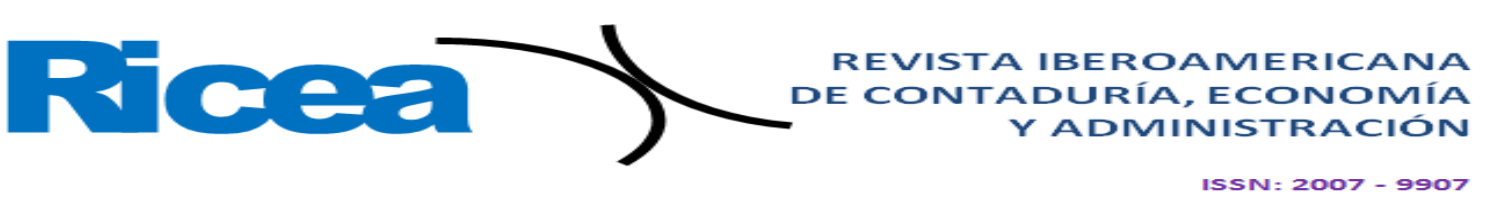

una dinámica con el informante que le permite descubrir accesos a su universo cultural (Guber, 2001).

Para el analizar el impacto del gasto público de la política social Sin Hambre se recurre a la utilización de técnicas para el análisis económico regional, y se utilizaron los datos del Censo Económico 2014 del Instituto Nacional de Estadística y Geografía [Inegi] (2014), para el municipio de Mártir de Cuilapan y el estado de Guerrero. El uso de la información mencionada le da sustento al análisis cuantitativo y permite la construcción de la tipología de las actividades económicas del municipio. Lo anterior por medio el índice de especialización productiva y la razón de productividades.

El análisis de base económica indica que una economía local puede dividirse en dos sectores: básico y no básico.

Sector básico: se integra por las actividades productivas y de servicios que dependen fundamentalmente de la demanda externa, manufactura, minería, actividades agropecuarias de exportación, y turismo.

Sector no básico: Conformado por actividades que dependen principalmente de la demanda interna, orientadas a la economía local y actividades del gobierno local.

Coeficientes de localización (CL): es un análisis económico regional para determinar la circunstancia relativa de una unidad territorial respecto a otra. Permitiendo comparar el tamaño relativo de un sector dentro de una región:

$$
\mathrm{CL}=\frac{\frac{E_{i j}}{E_{i}}}{\frac{N_{j}}{N}}
$$

$E_{i j}=$ Población ocupada en rama $j$ en región $i$.

$E_{i}=$ Población total ocupada en la región $i$.

$N_{j}=$ Población ocupada en rama $j$ a nivel nacional.

$N=$ Población ocupada a nivel nacional.

(...) Si $\mathrm{CL}=1$, es que se tiene una producción local suficientes para abastecer su demanda, pero no hay excedentes para exportar, se puede concluir que la actividad está localizada. 


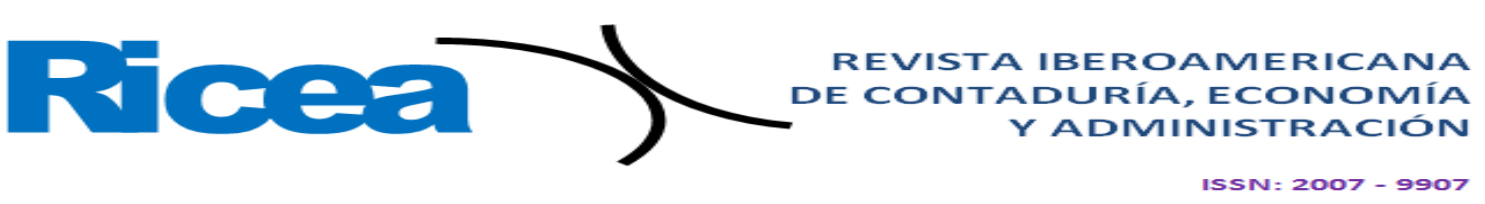

Si CL $<1$, significa que existe insuficiencia en la producción local, por tanto, es necesario importar bienes y/o servicios para abastecer la demanda local, la actividad está poco localizada.

Si CL > 1, implica que la economía local tiene una especialización en esta actividad, la producción es mayor a la demanda local, por tanto, hay posibilidades para exportar (Torres, Rozga, García y Delgadillo, 2009, pp. 42).

El método de estimación de empleo básico se realiza a través de la razón entre productividades $V_{i}^{t}$, y se calcula como: $V_{i}^{t}=p_{i}^{t} / P_{i}^{t}$.

Donde $p_{i}^{t}$ es la productividad a escala municipal, se estima de la siguiente forma:

$$
p_{i}^{t}=v a b_{i}^{t} / e_{i}^{t}
$$

$v a b_{i}^{t}$ : Valor agregado bruto municipal en la actividad $i$ en el año $t$.

$e_{i}^{t}$ : Empleo municipal en la actividad $i$ en el año $t$.

$P_{i}^{t}$ : Es la productividad a escala estatal, se estima de la siguiente forma:

$$
P_{i}^{t}=v a b_{i}^{t} / E_{i}^{t}
$$

$v a b_{i}^{t}$ : Valor agregado bruto estatal en la actividad $i$ en el año $t$.

$E_{i}^{t}$ : Empleo estatal en la actividad $i$ en el año $t$ (Morales, 1998, p. 27).

Después de haber estimado la productividad a escala municipal y estatal, se prosigue a calcular la razón entre productividades, cuyos resultados expresan si $V_{i}^{t}$ es igual, mayor o menor a 1.

Si la productividad municipal es mayor a la productividad estatal: $V_{i}^{t}>1$, localmente se requiere menos empleos para generar una unidad de producto que los que se requieren en escala estatal.

Si la productividad municipal es menor a la productividad estatal: $V_{i}^{t}<1$, se sobrestimaría la participación municipal en la producción estatal y con ello el empleo básico correspondiente (Morales, 1998, p. 28). 


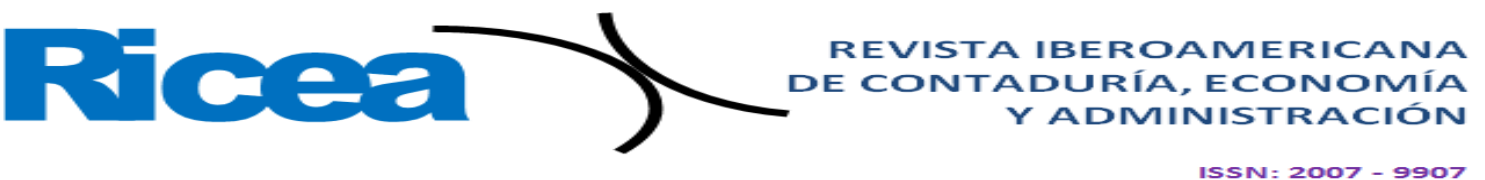

En la tabla 1 se aprecia la estructura de la tipología de las actividades económicas, donde cada sector económico municipal con respecto al estatal se identifica por su posición de especialización en el sector básico o no básico de la economía y por su desempeño productivo (Morales, 1998).

Tabla 1. Tipología de las actividades económicas

\begin{tabular}{|l|r|r|}
\cline { 2 - 3 } \multicolumn{2}{l|}{} & \multicolumn{2}{|c|}{$\begin{array}{c}\text { Desempeño } \\
\text { (productividad) }\end{array}$} \\
\cline { 2 - 4 } & \multicolumn{1}{|c|}{$V_{i}^{t}<1$} & \multicolumn{1}{c|}{$V_{i}^{t}>1$} \\
\hline
\end{tabular}

Fuente: Elaboración propia

\section{La CNCH en el municipio de Mártir de Cuilapan}

En el 2013, Mártir de Cuilapan (véase figura 1) fue seleccionado como municipio piloto para iniciar los trabajos de la CNCH. El Lic. José Guadalupe Rivera Ocampo (21 de abril de 2017, entrevista), quien se desempeñaba como presidente municipal (2012-2015), manifestó que el municipio fue seleccionado "por ser pequeño, por ser municipio pobre, por ser municipio que tiene 


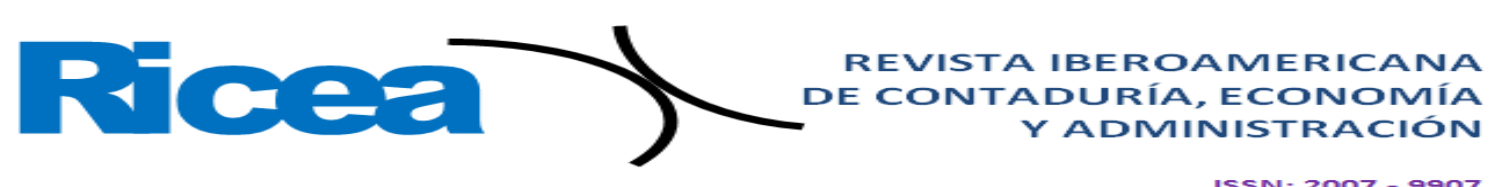

una mezcla de lenguas, tenemos zonas indígenas y también uno de los grandes motivos creo que fue, la cercanía y el tema de seguridad que se tomó en cuenta”.

Figura 1. Mapa de ubicación del Municipio de Mártir de Cuilapan, Guerrero

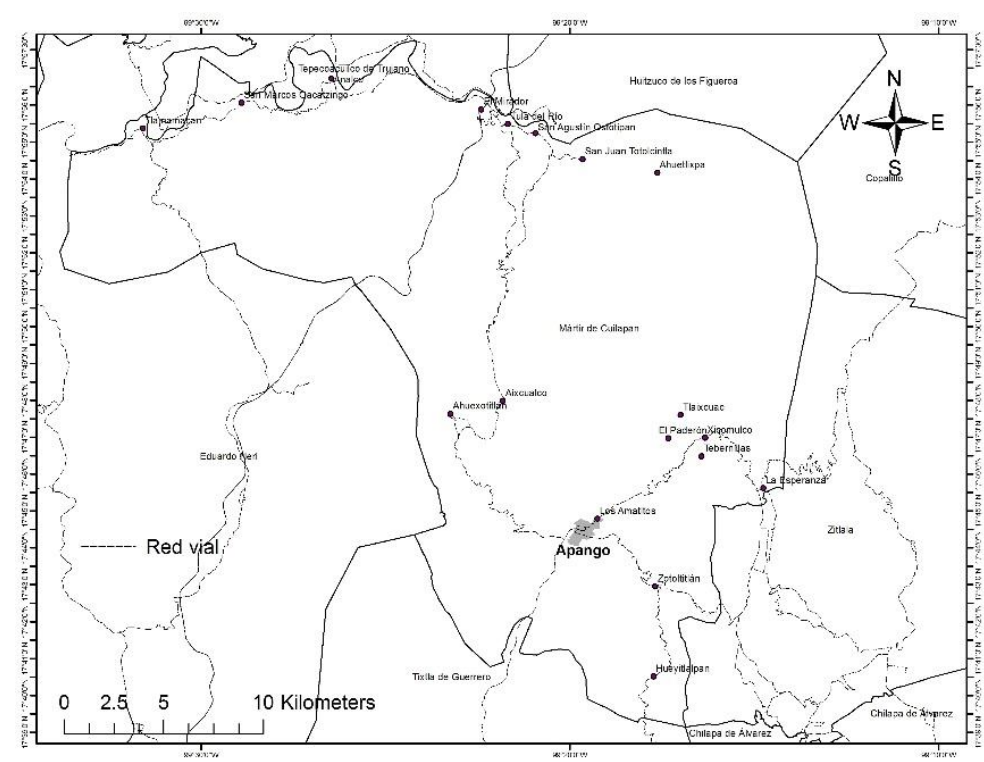

Fuente: Elaboración propia con base al Marco Geoestadístico 2016, INEGI.

Por primera vez, el Gobierno federal tomó en cuenta al municipio para impulsar una estrategia de participación comunitaria a partir de la identificación de las necesidades básicas de la población, lo que se apoyó en información estadística proporcionada por el Coneval, el Consejo Nacional de Población (Conapo), el Inegi y distintas dependencias gubernamentales. Los datos obtenidos fueron enviados a la Comisión Intersecretarial, que tenía la tarea de "coordinar, articular y complementar las acciones, programas y recursos necesarios para el cumplimiento del objetivo del programa Sin Hambre" (DOF, 22 de enero de 2013), y la cual, a su vez, la remitiría a las delegaciones de las dependencias federales para su análisis, así como para ejecutar acciones coordinadas.

La Cruzada contra el Hambre, para cumplir el objetivo de aumentar la producción y el ingreso de los productores rurales, canalizó las demandas de financiamiento a través de dependencias federales como el Instituto Nacional de la Economía Social (Inaes) de la Secretaría de Economía, la Comisión Nacional para el Desarrollo de los Pueblos Indígenas (CDI), la Secretaría de Agricultura, Ganadería, Desarrollo Rural, Pesca y Alimentación (Sagarpa), la Secretaría de Desarrollo Agrario, Territorial y Urbano (Sedatu) y la Secretaría de Desarrollo Social (Sedesol), quienes otorgaron apoyos económicos con el fin de mejorar el indicador de carencia por 


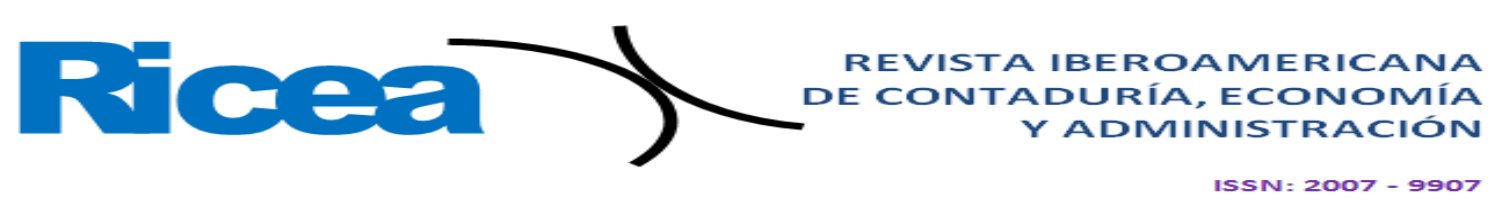

ingresos de la población objetivo, que se encontraba por debajo de la línea de bienestar mínimo, así como con la meta de propiciar el fortalecimiento de los espacios productivos locales.

Atendiendo al llamado del presidente de México para iniciar los trabajos de la $\mathrm{CNCH}$ en el mes de marzo del año 2013, el Gobierno municipal de Mártir de Cuilapan solicitó al Gobierno federal que la población tuviera una participación directa en los programas, debido al grado de desconfianza que tenía esta última respecto de los programas y las dependencias federales y estatales (Rivera, 21 de abril de 2017, entrevista). En este contexto, una de las principales acciones promovidas por la Sedesol fue la conformación de comités comunitarios, quienes se encargaron de identificar la población objetivo y sus necesidades, para ser incorporados a los programas federales.

De acuerdo con el Censo de Población y Vivienda 2010 (Inegi, 2010), el municipio de Mártir de Cuilapan contaba con una población de 17702 habitantes, de los cuales $48 \%$ eran hombres y $52 \%$ mujeres. Además, $43.4 \%$ de la población de cinco años y más era hablante de una lengua indígena. El número de comunidades del municipio era de 19: $5 \%$ urbanas (la cabecera municipal) y $95 \%$ rurales.

En el año 2011, el Coneval dio a conocer las estimaciones del índice de rezago social 2010 a nivel municipal y por localidad. En el caso del municipio de Mártir de Cuilapan, se tomaron en cuenta 18 localidades (no se consideró la localidad de Los Amatitos) para determinar el índice y grado de rezago social. Los resultados mostraron que $5.6 \%$ de las localidades tenía un grado de rezago social bajo, $50 \%$ un grado de rezago social medio y $44.4 \%$ un grado de rezago social alto. Si tomamos en cuenta la población, 24.6 \% vivía en una comunidad con rezago social bajo, $49 \%$ en localidades con rezago social medio y $25.7 \%$ en localidades con rezago social alto. Lo anterior refleja que $74.2 \%$ de la población tenía la capacidad de acceder a los servicios educativo, de salud, básicos de vivienda y de calidad de los espacios de vivienda como resultado de la cobertura de los programas sociales federales y estatales; sin embargo, tomando en cuenta que $95 \%$ de las localidades del municipio eran rurales, colocaba a estas en situación de vulnerabilidad ante perturbaciones económicas y sociales que les imposibilitaban transitar los horizontes de la desigualdad económica y social.

En la tabla 2 se describen los apoyos otorgados al municipio y sus comunidades en el marco del programa Sin Hambre de la CNCH en el año 2013. Los conceptos atendidos por la Sedesol, la Sagarpa, la Secretaría de Comunicaciones y Transportes (SCT), la Secretaría de Medio Ambiente y Recursos Naturales (Semarnat), la Secretaría de Economía y la CDI fueron: 


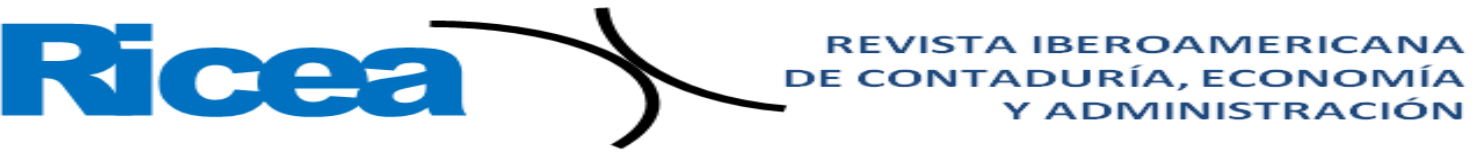

ISSN $=2007-9907$

- Transferencias monetarias,

- $\quad$ Apoyo a la producción no agrícola y generación de ingreso,

- $\quad$ Apoyo al aumento y mejoramiento de producción agropecuaria, apícola, cría y explotación de animales, aprovechamiento forestal, para generación de ingreso y

Apoyo para el impulso de cadenas productivas para generación de ingresos.

Como se observa en la tabla 2, el gasto público destinado al municipio de Mártir de Cuilapan en transferencias monetarias recibió la cantidad de 26445917.51 de pesos, de los cuales $17.4 \%$ se distribuyó en la cabecera municipal y el resto de las comunidades recibieron $82.6 \%$. Para apoyo a la producción no agrícola y generación de ingreso, se recibieron 14265469.38 pesos, de los cuales $41.7 \%$ se destinó a la cabecera municipal y $58.3 \%$ al resto de las localidades. Para el mejoramiento de producción agropecuaria, apícola, cría y explotación de animales y aprovechamiento forestal para generación de ingreso, se destinaron 11224888.30 pesos, de los cuales $11 \%$ se distribuyó en la cabecera municipal y $89 \%$ en las localidades rurales. Por último, el apoyo para el impulso de cadenas productivas para generación de ingresos (mezcal) fue de 1782 840 pesos, de este monto $55.3 \%$ se destinó a la cabecera municipal y $44.7 \%$ al resto de las comunidades. 


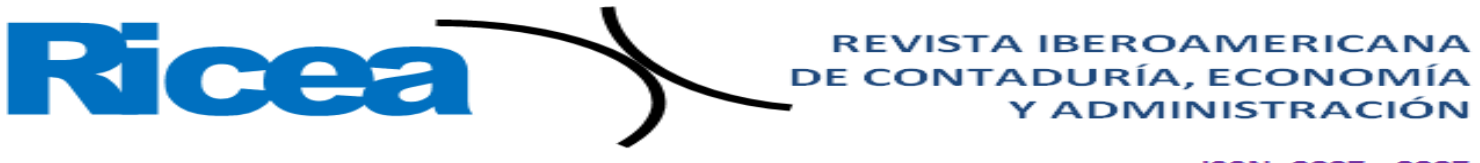

Tabla 2. Gasto público destinado al municipio de Mártir de Cuilapan en el marco del programa Sin Hambre de la CNCH, 2013

\begin{tabular}{|c|c|c|c|c|c|c|c|c|}
\hline \multirow{2}{*}{ Indicador } & \multirow{2}{*}{ Concepto } & \multirow{2}{*}{$\begin{array}{l}\text { Dependencias } \\
\text { participantes }\end{array}$} & \multicolumn{2}{|c|}{$\begin{array}{c}\text { Municipio de Mártir } \\
\text { de Cuilapan }\end{array}$} & \multicolumn{2}{|c|}{ Cabecera municipal } & \multicolumn{2}{|c|}{ Resto del municipio } \\
\hline & & & $\begin{array}{l}\text { Gasto } \\
\text { Total }\end{array}$ & $\%$ & Gasto & $\%$ & Gasto & $\%$ \\
\hline \multirow{4}{*}{$\begin{array}{c}\text { Carencia } \\
\text { por ingresos } \\
\text { por debajo } \\
\text { de la línea } \\
\text { de bienestar } \\
\text { mínimo }\end{array}$} & $\begin{array}{l}\text { Transferencias } \\
\text { monetarias }\end{array}$ & \begin{tabular}{|l} 
Sedesol, \\
Sagarpa, SCT y \\
Semarnat
\end{tabular} & 26445917.51 & 49.2 & 4606689.50 & 17.4 & 21839228.01 & 82.6 \\
\hline & $\begin{array}{l}\text { Apoyo a la producción } \\
\text { no agrícola y } \\
\text { generación de ingreso. }\end{array}$ & $\begin{array}{l}\text { Sedesol, } \\
\text { Sagarpa y } \\
\text { Secretaría de } \\
\text { Economía }\end{array}$ & 14265469.38 & 26.6 & 5950537.40 & 41.7 & 8314931.98 & 58.3 \\
\hline & $\begin{array}{l}\text { Apoyo al aumento y } \\
\text { mejoramiento de } \\
\text { producción } \\
\text { agropecuaria, apícola, } \\
\text { cría y explotación de } \\
\text { animales, } \\
\text { aprovechamiento } \\
\text { forestal, para } \\
\text { generación de ingreso. }\end{array}$ & $\begin{array}{l}\text { Sagarpa, } \\
\text { Semarnat, CDI } \\
\text { y Secretaría de } \\
\text { Economía }\end{array}$ & 11224888.30 & 20.9 & 1239781.66 & 11.0 & 9985106.64 & 89.0 \\
\hline & $\begin{array}{l}\text { Apoyo para el impulso } \\
\text { de cadenas productivas } \\
\text { para generación de } \\
\text { ingresos: Mezcal }\end{array}$ & $\begin{array}{l}\text { Secretaría de } \\
\text { Economía }\end{array}$ & 1782840.00 & 3.3 & 985070.00 & 55.3 & 797770.00 & 44.75 \\
\hline & \multicolumn{2}{|c|}{ Inversión total } & 53719115.19 & 100.0 & 12782078.56 & 23.8 & 40937036.63 & 76.2 \\
\hline
\end{tabular}

Fuente: Elaboración propia con base en Secretaría de Bienestar (s. f.)

Una de las primeras acciones realizadas por parte de Sin Hambre en el 2013, a través de los programas de Oportunidades, Empleo Temporal, Procampo y Desarrollo de Zonas Prioritaria para enfrentar la falta de ingreso, principal indicador de pobreza en el municipio piloto, fue la entrega de transferencias económicas, que representó $49.2 \%$ del gasto público total realizado. En tanto que para mejorar y aumentar la producción, agropecuaria, apícola, cría y explotación de animales, y aprovechamiento forestal, se destinó tan solo $20.9 \%$, que junto con el apoyo para el impulso de cadenas productivas para generación de ingresos (mezcal) representó 25.2\%. De lo anterior se deduce que el apoyo para el desarrollo y fortalecimiento de las actividades productivas fue menor a las transferencias directas a los beneficiarios. En consecuencia, en vez de generar emprendimientos que diversificaran y fortalecieran las actividades agrícolas locales, se 


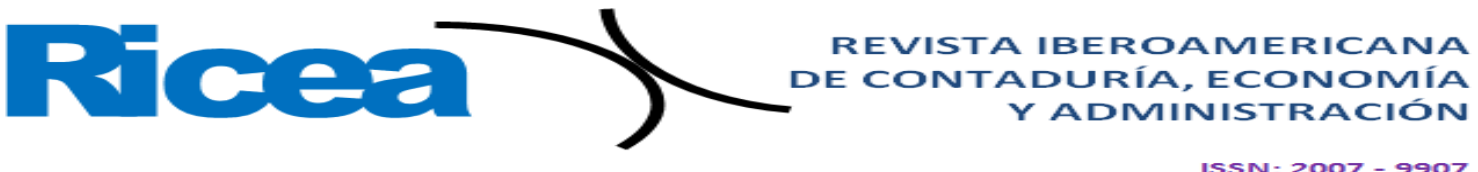

fortalecieron los lazos de dependencia que inhiben la posibilidad de que la población rompa con la trampa de pobreza.

Con el fin de observar el impacto del gasto público realizado en el marco de la $\mathrm{CNCH}$, se calcularon los indicadores de productividad y especialización de los sectores económicos municipales, con base en la información proporcionada por el Censo Económico 2014 del Inegi (2014).

En la tabla 3 se presentan los resultados referentes a los coeficientes de especialización y razones de productividad por sector económico, lo que permite elaborar una tipología de las actividades productivas, de acuerdo con lo establecido en la metodología.

Tabla 3. Coeficientes de especialización y razones de productividad por sectores económicos en el municipio de Mártir de Cuilapan, Gro., 2014

\begin{tabular}{|l|c|c|}
\hline Sectores económicos & $\begin{array}{c}\text { Coeficiente de especialización } \\
(\mathbf{C l})\end{array}$ & $\begin{array}{c}\text { Razón de productividad } \\
\left(\boldsymbol{V}_{\boldsymbol{i}}^{\boldsymbol{t}}\right)\end{array}$ \\
\hline $31-33$ & 4.46 & 0.18 \\
\hline 43 & 0.12 & 0.10 \\
\hline 46 & 0.56 & 0.19 \\
\hline $48-49$ & 0.12 & 0.98 \\
\hline 56 & 0.44 & 0.10 \\
\hline 62 & 0.19 & 0.12 \\
\hline 71 & 0.32 & 0.35 \\
\hline 72 & 0.42 & 0.55 \\
\hline 81 & 0.76 & 0.08 \\
\hline
\end{tabular}

* Sectores económicos: 31-33: Industria manufacturera. 43: Comercio al por mayor. 46: Comercio al por menor. 4849: Transportes, correos y almacenamiento. 56: Servicio de apoyo a los negocios y manejo de desechos y servicios de remediación. 62: Servicios de salud y de asistencia social. 71: Servicios de esparcimiento, culturales y deportivos, y otros servicios recreativos. 72: Servicios de alojamiento temporal y de preparación de alimentos y bebidas. 81: Otros servicios excepto actividades gubernamentales

Fuente: Elaboración propia con base en Inegi (2014)

Los resultados obtenidos para los sectores económicos 31-32, referentes a industrias manufactureras, muestra que las actividades económicas de este sector forman parte del básico de la economía del municipio; es decir, actividades productivas y de servicios que dependen fundamentalmente de la demanda externa, aunque su razón de productividad muestra que la 


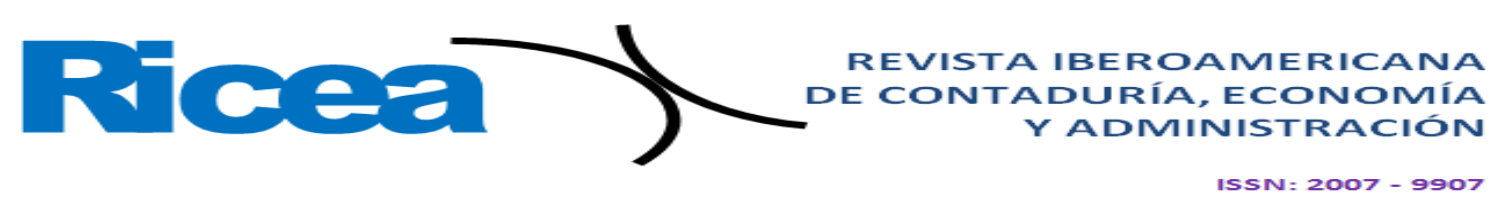

productividad municipal es menor que la estatal. En consecuencia, los sectores en mención tienen una posición dinámica y desempeño no competitivo. Los establecimientos económicos de estos sectores requieren inversiones para mejorar su productividad y aprovechar su posición. Cabe señalar que la producción de mezcal y miel son las más dinámicas y competitivas en el municipio.

Dado que el municipio se caracteriza por ser productor de mezcal de forma artesanal y de miel, el Inaes, a través del Programa de Fomento a la Economía Social, apoyó a los productores de mezcal y la CDI a los productores de miel, y otorgaron financiamiento para el desarrollo de esas actividades productivas en el 2013. A pesar de ello, los productores de mezcal entrevistados coincidieron en señalar que hacían falta recursos financieros para mejorar las técnicas y proceso de producción, instaurar marcas propias y sistemas de envasado. Esto para estar en condiciones de cumplir con las normas del Consejo Regulador de Mezcal y poder obtener la certificación como productores, lo que posibilitaría la venta a nivel nacional y en el extranjero de su producción; los productores de miel utilizarían el financiamiento otorgado para certificar su producto y poder exportar hacia Europa.

Los sectores económicos 43, 46, 48- 49, 56, 62, 71, 72 y 81, como se observa en la tabla 4, forman parte del sector no básico de la economía municipal, el cual está integrado por actividades económicas que dependen principalmente de la demanda interna, orientados a la economía local. Por lo tanto, se sitúan en una posición no dinámica y con desempeño no competitivo. En estas actividades se requiere inducir la productividad. La productividad de las actividades económicas se puede incrementar por medio del aumento de la inversión que permita mejorar las técnicas de producción y los mecanismos de distribución de los productos. En la tabla 4 se observa la ausencia de sectores económicos ubicados en el primer cuadrante, lo que nos indica que las actividades productivas no se caracterizan por impulsar el desarrollo de la economía local. En general, la producción del municipio es para el consumo local, salvo la producción de mezcal y miel. 


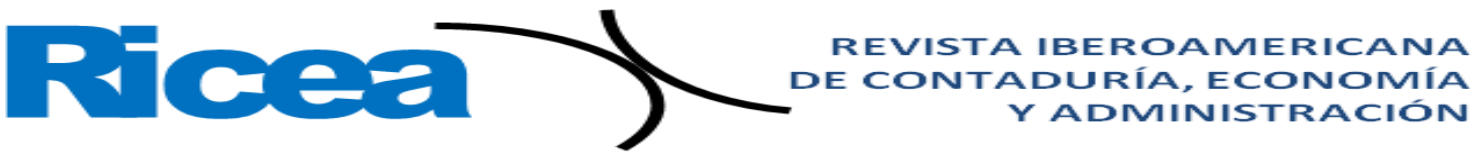

ISSN $=2007-9907$

Tabla 4. Tipología de las actividades económicas del municipio de Mártir de Cuilapan

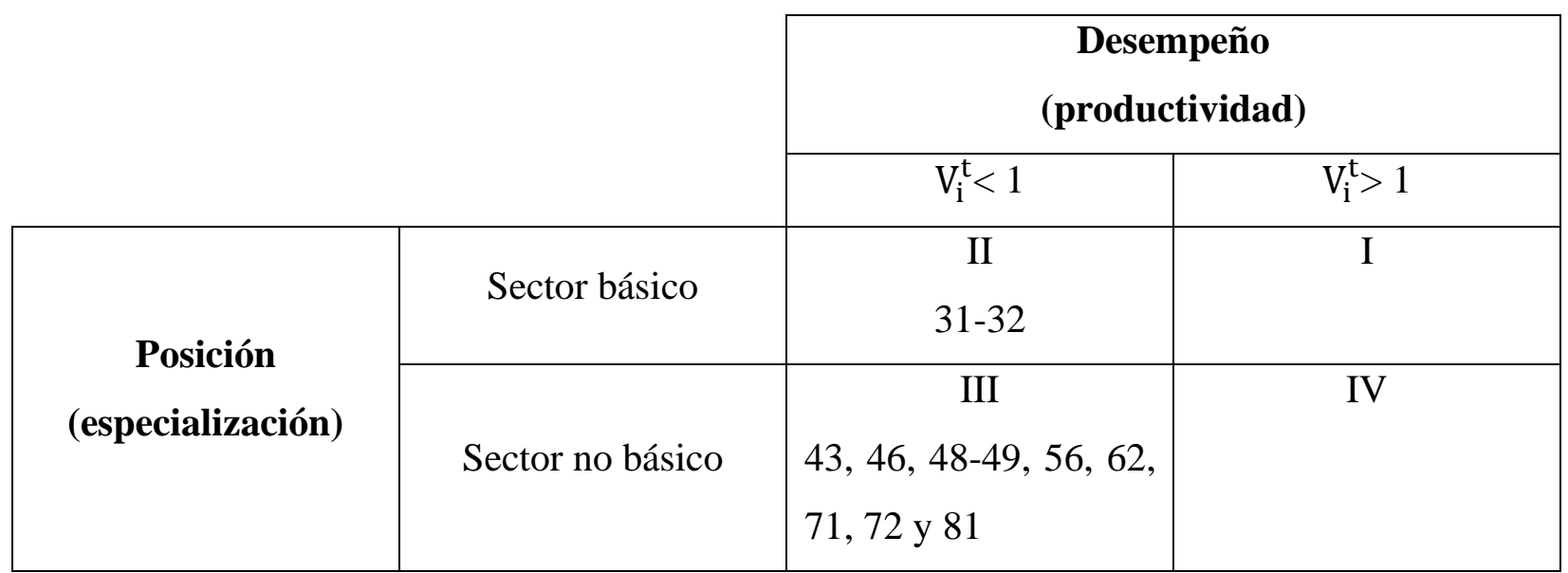

Fuente: Elaboración propia

Los datos anteriores permiten señalar que se dio continuidad al modelo de política social de transferencias económicas, sustentado en la centralización y focalización (Keynes, 1943), con una limitada participación de la comunidad en la toma de decisiones, lo que contribuyó a inhibir un desarrollo a favor de ellas. Así también, se evidenció la ausencia de coordinación por parte de las dependencias federales, lo que impidió la unidad en la acción de estas en beneficio de la población (Carlos Rojas Gutiérrez, 23 de enero de 2017, entrevista).

\section{Conclusiones}

A seis años de haberse implementado el programa de la $\mathrm{CNCH}$ en el municipio de Mártir de Cuilapan, en el estado de Guerrero, el impacto de esta no fue el esperado. Las evidencias muestran ausencia de coordinación entre los diferentes órdenes de gobierno, aunado a la falta de capacidad técnica y de gestión en la planeación por parte de los integrantes del H. Ayuntamiento. Las entrevistas realizadas al presidente municipal y al director del Inaes proyectan los efectos de carencia de un ambiente propicio que promueva la coordinación interinstitucional entre los órdenes de gobierno a nivel federal, estatal y municipal, así como la impericia para establecer una relación entre el Estado y la población que permitiera mayor libertad de participación en la toma de decisiones, con el fin de romper con el esquema de centralización en la toma de decisiones y de focalización en la asignación de recursos, todo lo cual inhibió las posibilidades de desarrollo desde una perspectiva territorial. 


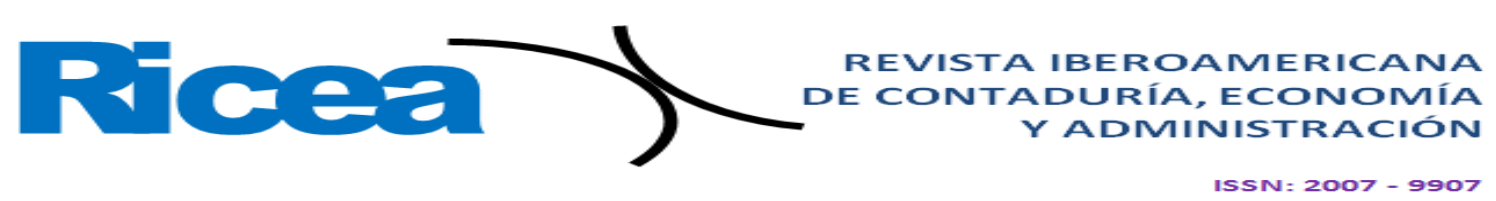

Si bien el objetivo de la estrategia de la $\mathrm{CNCH}$ era combatir la pobreza y fortalecer las actividades productivas, al darle mayor énfasis a las transferencias monetarias $(49.2 \%$ del gasto público destinado al municipio de Mártir de Cuilapan en el marco del programa Sin Hambre de la $\mathrm{CNCH}, 2013)$, del cual $82 \%$ se destinó a las comunidades rurales, a diferencia del gasto destinado al apoyo para el aumento de la producción e impulso de cadenas productivas, a lo que se le destinó $24.2 \%$ (82.9\% se orientó a las comunidades rurales del municipio), el financiamiento de proyectos productivos se llevó a cabo sin analizar su factibilidad, sin considerar la complejidad y el dinamismo de la pobreza a escala territorial, y sin tomar en cuenta la potencialidad de los recursos naturales y los saberes locales con que cuentan las comunidades. Lo anterior impidió territorializar la estrategia para que las comunidades lograran un desarrollo económico territorial en la perspectiva de la sustentabilidad social.

La elaboración de una tipología de las actividades económicas del municipio de Mártir de Cuilapan permite observar el impacto del gasto público que se realizó en el marco de la $\mathrm{CNCH}$, para lo cual se calcularon los indicadores de productividad y especialización de los sectores económicos municipales, con base en la información suministrada por el Censo Económico 2014 realizado por el Inegi (2014). La mayoría de los sectores económicos del municipio son parte del sector no básico de la economía, tienen una posición no dinámica y no tienen un desempeño competitivo; y por lo tanto, los establecimientos de estos sectores requieren de inversiones que estimule el crecimiento de su productividad. Solo los sectores económicos 31-32, referentes a industrias manufactureras, son parte del sector básico de la economía. En consecuencia, los sectores mencionados tienen una posición dinámica y un desempeño no competitivo; los establecimientos de estos sectores requieren inversión para mejorar su productividad y aprovechar su posición. Tanto los datos del Inegi como las entrevistas realizadas a exfuncionarios municipales y productores permiten indicar que la producción de mezcal y miel son las más dinámicas y competitivas en el municipio.

A pesar de que la mayoría del gasto público se orientó a las comunidades rurales del municipio, los resultados obtenidos indican que el territorio y su realidad son elementos que imponen la necesidad de repensar los enfoques de la política social. La política social se debe sustentar en una planeación territorial que permita la coordinación entre los distintos órdenes de gobierno, actores y sectores sociales para la elaboración y fortalecimiento de una política social territorializada; que se centre en el cómo, el dónde y para qué del desarrollo socioterritorial. Es decir, deben adaptarse de manera flexible a las condiciones de los territorios generando escenarios propicios para el desarrollo local con un enfoque de sustentabilidad social, con el fin de reducir el 


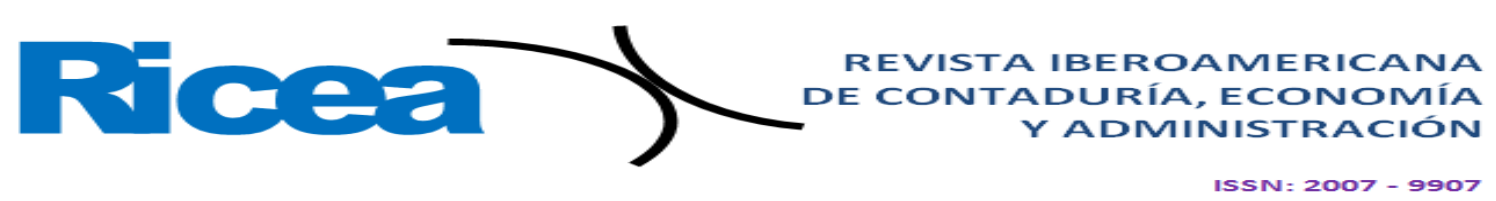

grado de vulnerabilidad de la población, alcanzar una menor dependencia de los programas sociales de transferencia económica y propiciar su salida de la trampa de pobreza.

En síntesis, la $\mathrm{CNCH}$, en vez de generar emprendimientos que diversificaran y fortalecieran las actividades agrícolas locales, propició lazos de dependencia económica y política que inhiben la posibilidad de que la población rompa con la trampa de pobreza.

\section{Referencias}

Adelantado, J. (2000). Cambios en el Estado del Bienestar. Políticas Sociales y Desigualdades en España. Barcelona, España: Icaria - UAB.

Boisier, S. (2003). Globalización, geografía política y fronteras. Anales de Geografía de la Universidad Complutense, (23), 21-39.

Cámara de Diputados. (2013). "Cruzada Contra el Hambre”. Análisis teórico conceptual, de marco jurídico, políticas públicas, derecho comparado y de opiniones especializadas. México: Dirección General de Servicios de Documentación, Información y Análisis.

Consejo Consultivo del Programa Nacional de Solidaridad. (1994). El Programa Nacional de Solidaridad. Ciudad de México, México: FCE.

Consejo Nacional de Evaluación de la Política de Desarrollo Social [Coneval]. (2015). Informe de Evaluación de la Política de Desarrollo Social en México 2014. México: Consejo Nacional de Evaluación de la Política de Desarrollo Social.

Consejo Nacional de Evaluación de la Política de Desarrollo Social [Coneval]. (2016). Glosario. México: Consejo Nacional de Evaluación de la Política de Desarrollo Social. Recuperado de http://www.coneval.org.mx/Evaluacion/Paginas/Glosario.aspx.

Diario Oficial de la Federación [DOF]. (22 de enero de 2013). Decreto por el que se establece el Sistema Nacional para la Cruzada Contra el Hambre. Diario Oficial de la Federación.

Esping-Andersen, G. (1993). Los tres mundos del estado de bienestar. Valencia, España: Ediciones Alfons el Magnanim - IVEI.

Fernández, A., Pedregal, B., Rodríguez, J. C., Pita, M. F. y Zoido, F. (2009). El concepto de cohesión territorial. Escalas de aplicación, sistemas de medición y políticas derivadas. Boletín de la AGE, (50), 157 - 172. 


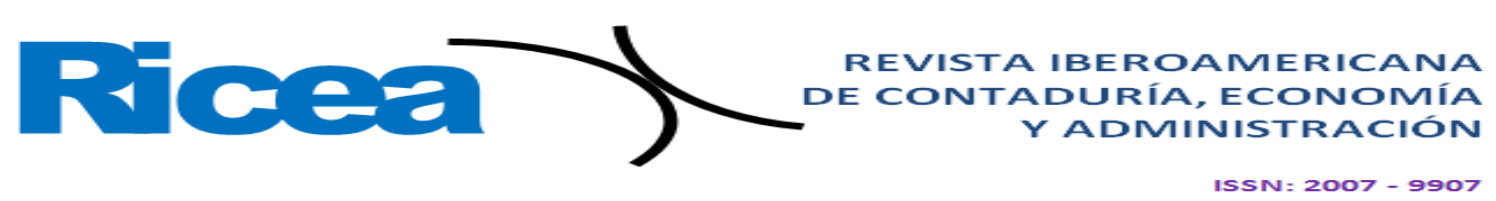

Foladori, G. (2002). Avances y límites de la sustentabilidad social. Economía, Sociedad y Territorio, 3(12), 621-637.

Fuentes, M. L. (22 de septiembre de 2015). México social: vulnerables y pobres. Excelsior. Recuperado de https://www.excelsior.com.mx/nacional/2015/09/22/1047065.

Gómez, H. (2015).Dos momentos de la participación en los programas de combate a la pobreza en México: El Programa Nacional de Solidaridad y la Cruzada Nacional Contra el Hambre. México: Programa Universitario de Estudios de Desarrollo de la Universidad Nacional Autónoma de México.

Guber, R. (2001). La entrevista etnográfica o el arte de la "no directividad". En La etnografía: Método, campo y reflexividad (pp. 75 - 100). Bogota, Colombia: Norma.

Hernández, R., Fernández, C., y Baptista, P. (2010). Metodología de Investigación. México: McGraw-Hill.

Hiernaux, D. y Lindon, A. (1993). El concepto de espacio y el analisis regional. Secuencia, (25), 89-110.

Instituto Nacional de Estadística y Geografía [Inegi]. (2010). Censo de Población y Vivienda 2010. México: Instituto Nacional de Estadística y Geografía. Recuperado de http://www.beta.inegi.org.mx/proyectos/ccpv/2010/default.html.

Instituto Nacional de Estadística y Geografía [Inegi]. (2014). Censos Económicos 2014. México: Instituto Nacional de Estadística y Geografía. Recuperado de http://www.beta.inegi.org.mx/app/saic/default.aspx.

Keynes, J. (1943). Teoría General de la Ocupación, el Interés y el Dinero. Ciudad de México, México: FCE.

Leff, E. (2000). Espacio, lugar y tiempo: la reapropiación social de la naturaleza y la construcción local de la racionalidad ambiental. Deselvomiento y medio ambiente, 42-56.

Marx, K. (2014). El capital: crítica de la economía política, tomo I. México: FCE.

Mayer-Foulkes, D. (2007). Fallas de mercado en capital humano La trampa intergeneracional de la pobreza en México. El Trimestre Económico, 74(295). Recuperado de http://www.eltrimestreeconomico.com.mx/index.php/te/article/view/375/573\#c1. 


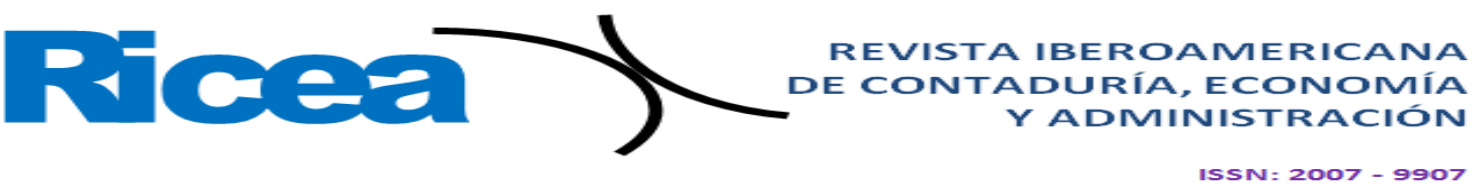

Smith, A. (1958). Investigación sobre la naturaleza y causas del la riqueza de las naciones. Ciudad de México, México: FCE.

Tello, C. (2010). Estancamiento económico, desigualdad y pobreza: 1982 - 2009. En Sobre la desigualdad en México (pp. 243-320 ). Ciudad de México, México: Universidad Autonoma de México, Facultad de Economía.

Torres, F., Rozga, R., García, A. y Delgadillo, J. (2009). Técnicas para el análisis regional. Desarrollo y Aplicaciones. Ciudad de México, México: Trillas.

United Nations World Commission on Evironment and Development. (1987). Our Common Future. New York, United States: Oxford University Press.

Vallance, S., Perkins, H. C. and Dixon, J. E. (2011). What is social sustainability? A clarification of concepts. Geoforum, 42(3), 342-348.

Yaschine, I. (2015). ¿Oportunidades? Política social y movilidad intergeneracional en México. Ciudad de México, México: Colmex-UNAM. 


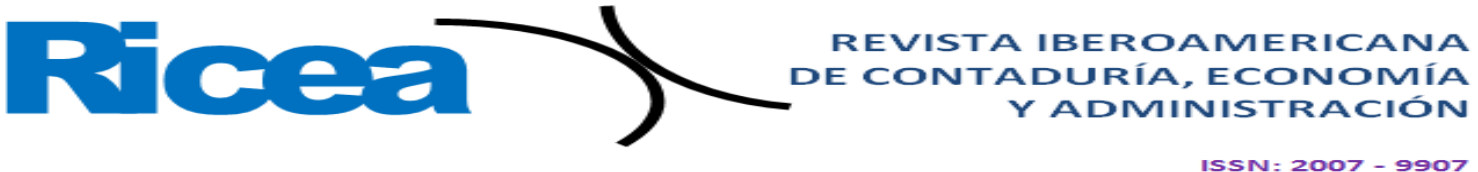

\begin{tabular}{|l|l|}
\hline Rol de Contribución & Autor (es) \\
\hline Conceptualización & $\begin{array}{l}\text { Iván Sánchez Ignacio Pedro Vidal Tello Almaguer Grado de } \\
\text { contribución: Igual» }\end{array}$ \\
\hline Metodología & $\begin{array}{l}\text { Iván Sánchez Ignacio Pedro Vidal Tello Almaguer Grado de } \\
\text { contribución: Igual» }\end{array}$ \\
\hline Software & NO APLICA \\
\hline Validación & Pedro Vidal Tello Almaguer \\
\hline Análisis Formal & $\begin{array}{l}\text { Iván Sánchez Ignacio Pedro Vidal Tello Almaguer « Grado de } \\
\text { contribución: Igual» }\end{array}$ \\
\hline Investigación & Iván Sánchez Ignacio \\
\hline Recursos & NO APLICA \\
\hline Curación de datos & NO APLICA \\
\hline $\begin{array}{l}\text { Escritura - Preparación del } \\
\text { borrador original }\end{array}$ & Iván Sánchez Ignacio \\
\hline $\begin{array}{l}\text { Escritura - Revisión } \\
\text { edición }\end{array}$ & $\begin{array}{l}\text { Iván Sánchez Ignacio Pedro Vidal Tello Almaguer Grado de } \\
\text { contribución: Igual» }\end{array}$ \\
\hline Visualización & $\begin{array}{l}\text { Iván Sánchez Ignacio Pedro Vidal Tello Almaguer Grado de } \\
\text { contribución: Igual» }\end{array}$ \\
\hline Supervisión & Nodro Vidal Tello Almaguer \\
\hline Adquisición de fondos & NO APLICA \\
\hline
\end{tabular}

